\title{
Optimization of the Rössing countercurrent decantation circuit for high-calc ore
}

\author{
by C.J. Anderson*, S.L. Rabie†, and N.K. Jansen van Rensburg‡
}

The Rössing Uranium countercurrent decantation (CCD) circuit is scheduled to process ore with a high calc index from 2017 to 2021. This material was found to be associated with poor settling performance in the CCD circuit. In order to quantify the root causes of the poor performance, bench-scale test work was conducted on the thickener feed. Thickener feed density and process control were identified as key areas for optimizing performance. Two alternative feedwell designs were developed; a simple shelf design and a forced dilution design. An automated control system was also devised to improve the consistency of underflow densities and overflow clarity. These modifications are currently being phased in at Rössing, with the process control upgrades and the feedwell on the terminal thickener being prioritized.

Keywords

countercurrent decantation, optimization, process control thickener, feedwell design. determine the settling characteristics of the high-calc material and identify which modifications would lead to the most costeffective improvements in performance with high-calc ore.

\section{Review of current CCD circuit}

Rössing currently operates a seven-stage CCD circuit, consisting of $2 \times 42.7 \mathrm{~m}$ clarifiers, $4 \times$ $42.7 \mathrm{~m}$ EIMCO thickeners, and $4 \times 68.5 \mathrm{~m}$ Dorr Oliver thickeners (both brand names are now the property of FLSmidth). A schematic of the circuit is given in Figure 1.

The thickeners were originally installed in 1977 and are designed as high-rate thickeners, operating with flocculent addition to the thickener feed launders. Despite the addition of flocculent, the thickeners operate with fairly low solids fluxes $\left(0.08 \mathrm{t} / \mathrm{h} / \mathrm{m}^{2}\right.$ on the $42.7 \mathrm{~m}$ thickeners and $0.12 \mathrm{t} / \mathrm{h} / \mathrm{m}^{2}$ on the $68.5 \mathrm{~m}$ thickeners). Thickener 7 was decommissioned for the past few years but came back online in Q2 2017.

\section{Thickener design}

The thickeners (Figure 2) are relatively shallow compared to most modern thickeners and have heavy truss rake structures. Slurry is introduced on launders which feed directly into the centre of the feedwells. The feedwells are annular in shape and direct flow downwards from the point of entry. The feed is diluted by overflow from the preceding CCD stage via another launder situated above the slurry launder. Flocculent is introduced via troughs onto the launders and most of the flocculation occurs on the feed launder before the material enters the feedwell.

\footnotetext{
* Hatch Africa, Johannesburg, South Africa.

+ Vietti Slurrytec, Johannesburg, South Africa.

¥ Rio Tinto, Melbourne, Australia.

(c) The Southern African Institute of Mining and Metallurgy, 2018. ISSN 2225-6253. This paper was first presented at the Uranium 2017 International Conference, 12-13 September 2017, Swakopmund Hotel, Swakopmund, Namibia.)
} 


\section{Optimization of the Rössing countercurrent decantation circuit for high-calc ore}

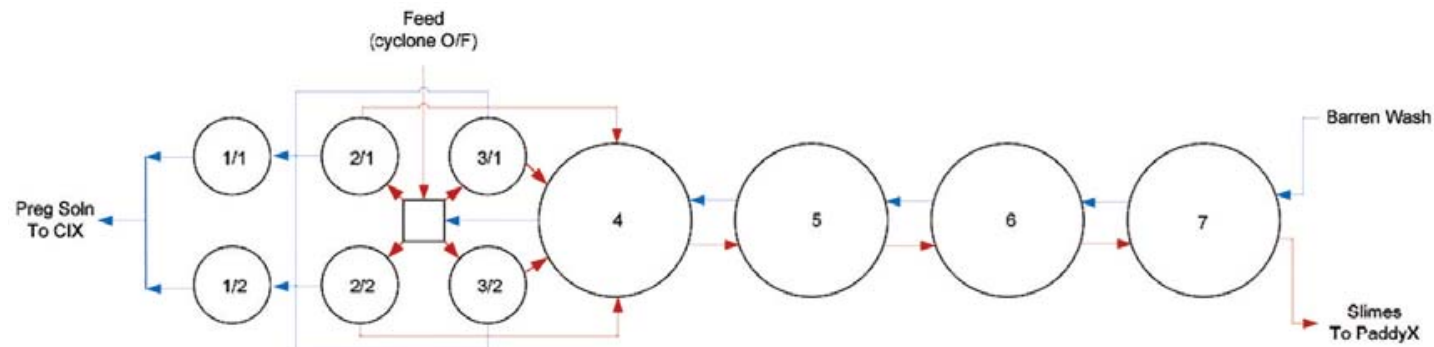

Figure 1-Schematic of the countercurrent decantation circuit at Rössing Uranium

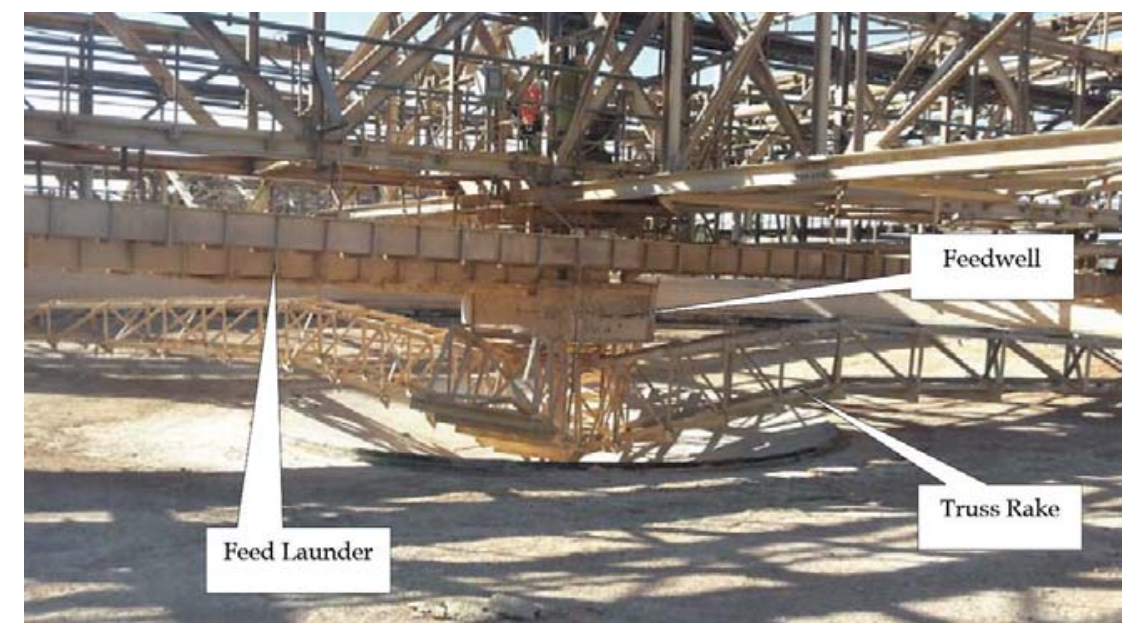

Figure 2-Internal structure of thickener 4
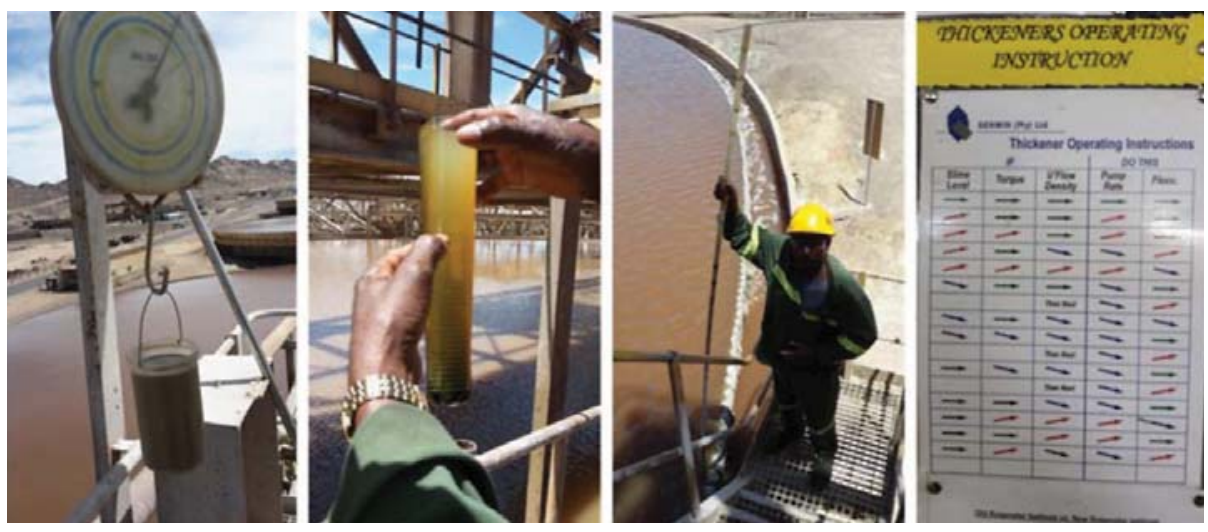

Figure 3-Process control measurements on CCD circuit

\section{Process control}

Process control (Figure 3 ) is a fairly manual style of operation, where operators take hourly samples of the thickener underflow for density and thickener overflow for clarity, using a clarity wedge. The mud bed interface is measured at the thickener perimeter using a graduated dipstick. This information is combined with the thickener rake torque measurement from the SCADA and interpreted using a set of control rules recommended by the flocculent vendor. The underflow pump speed and flocculent dose are adjusted by the control room operator so as to maintain a target underflow density, mud bed height, rake torque, and overflow clarity.

\section{Test work methodology}

In order to assess the circuit changes required, it was necessary to gather data from the plant when operating with both normal-calc ore and high-calc ore. To achieve this, a team from Hatch and Vietti Slurrytec visited Rössing from 713 April 2016. Rössing arranged for both normal and highcalc material to be campaigned through the plant during the test work. For these tests, the low-calc sample had a calc index of approximately $8 \mathrm{~kg} / \mathrm{t}$ and the high-calc a calc index of approximately $16 \mathrm{~kg} / \mathrm{t}$.

Samples were taken of the CCD circuit feed. The test work included both static and dynamic settling tests aimed at identifying the optimal thickening conditions for high-calc 


\section{Optimization of the Rössing countercurrent decantation circuit for high-calc ore}

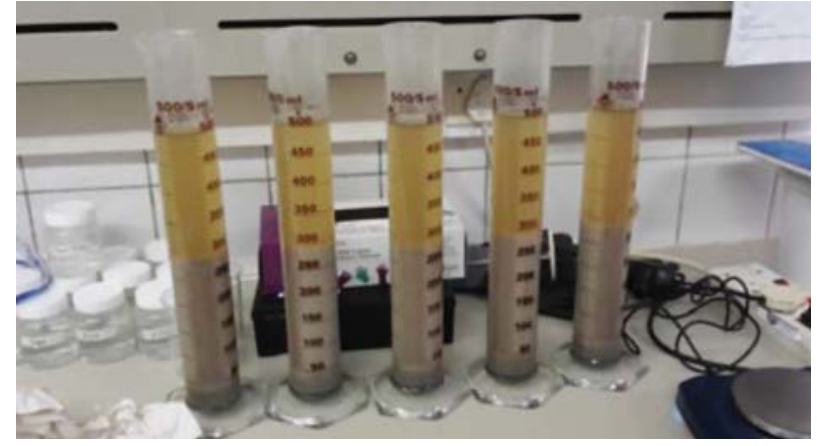

Figure 4-Static sedimentation tests

ore. In addition, SCADA data was collected from site, coinciding with normal and high-calc conditions, to assess the change in plant performance as a result of the feed material.

\section{Static sedimentation tests}

Test work was performed using a series of $500 \mathrm{ml}$ measuring flasks as shown in Figure 4. The static sedimentation tests included:

- Flocculent type screening

> Optimization of the feed slurry solids concentration

$>$ Optimization of flocculent demand

> Static settling rate.

\section{Bench-top dynamic settling tests}

The dynamic thickening tests were designed to determine:

- The optimum thickening area required for a specific process mass flow $(\mathrm{t} / \mathrm{h})$

> The mud bed accumulation and consolidation properties under dynamic batch operating conditions, on which a suitable control philosophy for a thickener can be based.

The tests were conducted in a $100 \mathrm{~mm}$ diameter benchtop dynamic thickener test rig, simulating high-rate (no pickets on the rake) thickening conditions. The dynamic tests included:

Solids flux tests

> $24 \mathrm{~h}$ mud bed consolidation tests.

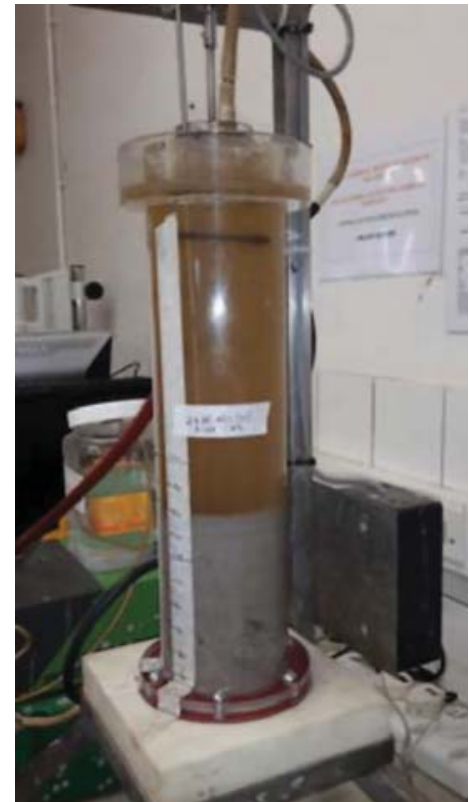

Figure 5-100 $\mathrm{mm}$ bench-top dynamic thickening test rig used

Note that the underflow densities obtained during the bench-top dynamic thickening tests are based on a 100-200 $\mathrm{mm}$ mud bed height and therefore essentially exclude the effect of extended mud bed height and residence time on the consolidation behaviour of the material. In order to fully assess the maximum underflow density achievable by fullscale thickening, further mud bed consolidation test work at a semi-pilot scale would be required.

\section{Results}

\section{Particle size distribution}

The particle size distribution of the CCD feed was measured during the survey. As expected, the high-calc material has a finer size distribution than normal material (Figure 6). This is most likely due to the softer ore components such as calcite affecting the grind in the mills, as well as increased leaching of the gangue minerals in the leach circuit.

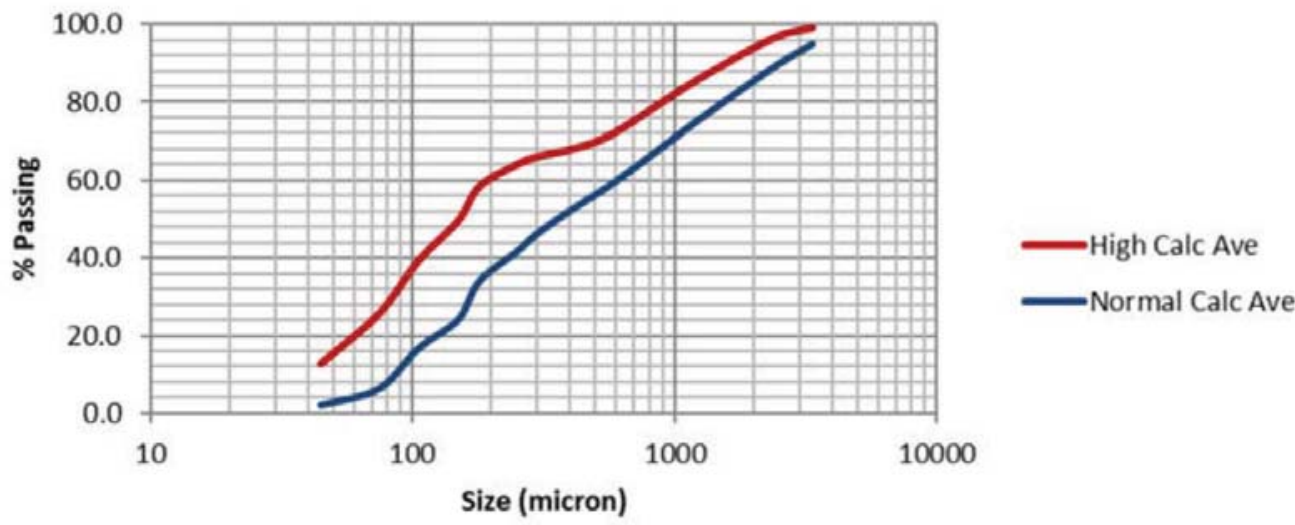

Figure 6-Average particle size distributions of normal and high-calc material during the survey 


\section{Optimization of the Rössing countercurrent decantation circuit for high-calc ore}

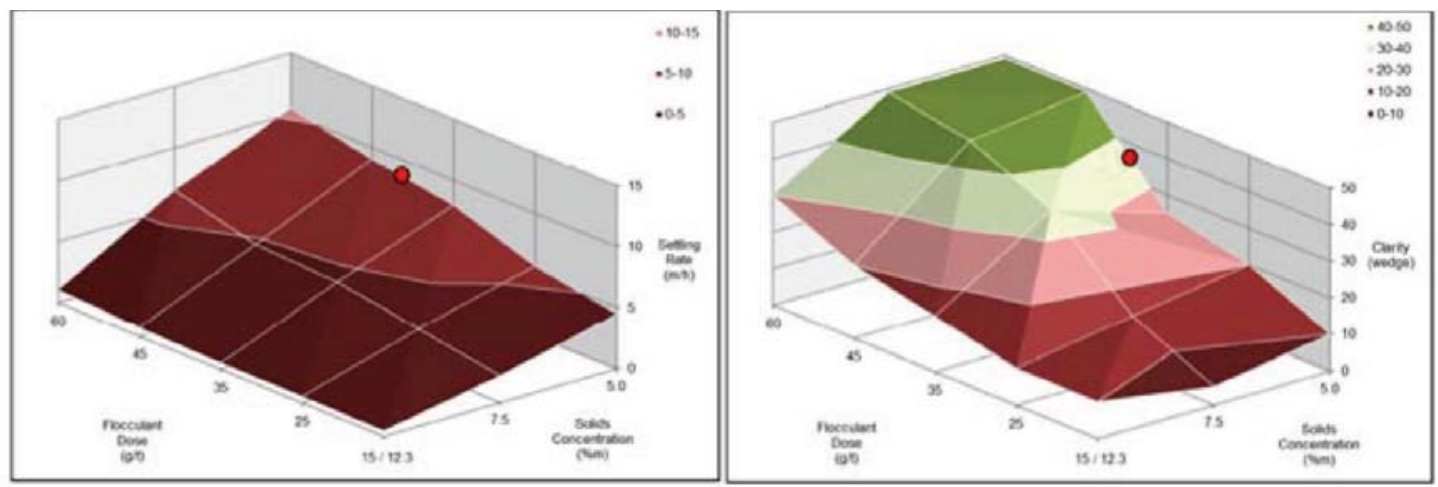

Figure 7 - Settling rate and overflow clarity at various flocculent dosages and feed concentrations for high-calc ore

\section{Static sedimentation tests}

Static sedimentation tests considered a range of flocculent dosages and feed densities and evaluated their impact on both settling rate and overflow clarity. Results of the highcalc ore settling tests are shown in Figure 7.

Figure 7 shows that although thickener performance is affected by flocculent dosage, the dominant factor in determining settling rate and clarity for high-calc ore is the feed solids concentration. At the current feed solids concentration of $12.3 \%(\mathrm{~m} / \mathrm{m})$ to the smaller $42.7 \mathrm{~m}$ thickeners, flocculent dosage has little impact on the settling rate and must be increased to $60 \mathrm{~g} / \mathrm{t}$ of CCD feed to achieve the target clarity of 30 .

In contrast, a decrease in the feed solids concentration to $5 \% \mathrm{~m} / \mathrm{m}$ resulted in an order-of-magnitude increase in the settling rate. However, a flocculent dosage of more than 35 $\mathrm{g} / \mathrm{t}$ was still required to achieve the target clarity of 30 .

The recommended plant conditions based on the static sedimentation tests are summarized in Table I. Although a feed concentration of $5 \% \mathrm{~m} / \mathrm{m}$ solids was tested in the static sedimentation tests, a value of $6 \% \mathrm{~m} / \mathrm{m}$ was considered more practical for the dynamic thickening tests.

\section{Dynamic sedimentation tests}

The effect of optimizing flocculent and feed concentration conditions was assessed in a series of dynamic settling tests. In these tests, the solids flux was varied to determine the capacity limitations of the thickeners. In the current operation, the small thickeners operate at a solids flux of $0.08 \mathrm{t} / \mathrm{h} / \mathrm{m}^{2}$ and the large thickeners at $0.12 \mathrm{t} / \mathrm{h} / \mathrm{m}^{2}$.

The low-calc sample was tested at the current plant feed concentration and flocculent dosage (refer Table I). The highcalc sample was tested at both the current plant conditions and at the recommended optimized conditions.

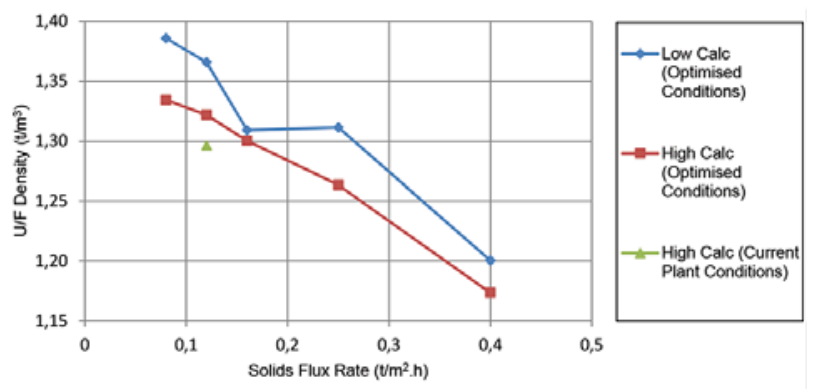

Figure 8-Effect of high-calc material on underflow density

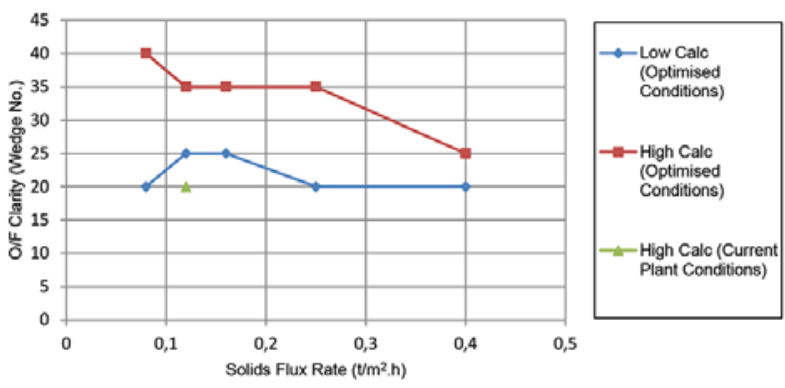

Figure 9-Effect of high-calc material on overflow clarity

Figures 8 and 9 show that at current plant conditions, the high-calc material results in a lower underflow density and overflow clarity than normal-calc material.

Should the plant conditions be optimized as recommended in Table I, a higher underflow density and overflow clarity can be achieved for high-calc material than with current plant conditions.

Table I

Optimum thickener conditions based on static sedimentation test work

\begin{tabular}{|l|c|c|}
\hline Operating conditions & Current practice for normal calc (42.7 m) thickeners) & Optimum for high-calc \\
\hline $\begin{array}{l}\text { Feed solids concentration (in feedwell) } \\
\text { Flocculent dosage }\end{array}$ & $\begin{array}{l}12 \% \mathrm{~m} / \mathrm{m} \\
\text { (2/ CCD feed }\end{array}$ & $6 \% \mathrm{~m} / \mathrm{m}$ \\
\hline
\end{tabular}




\section{Optimization of the Rössing countercurrent decantation circuit for high-calc ore}

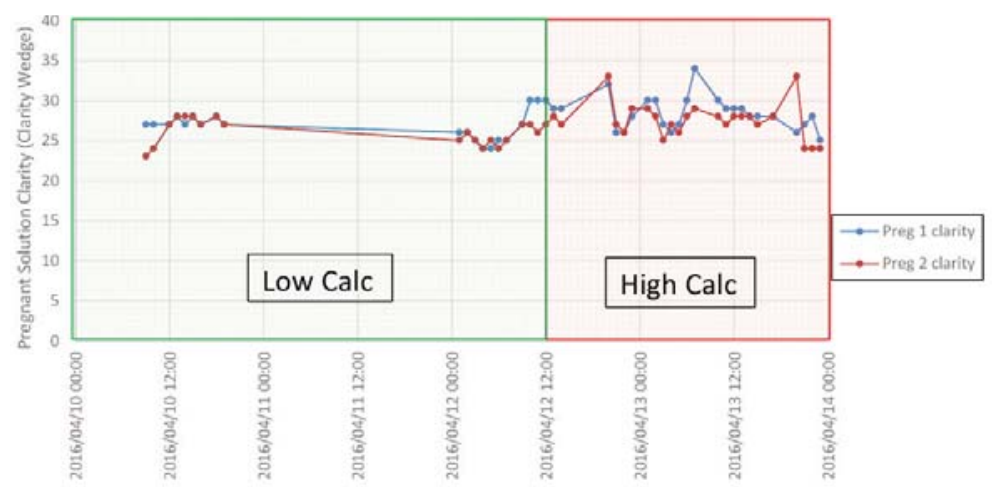

Figure 10-Pregnant solution clarity

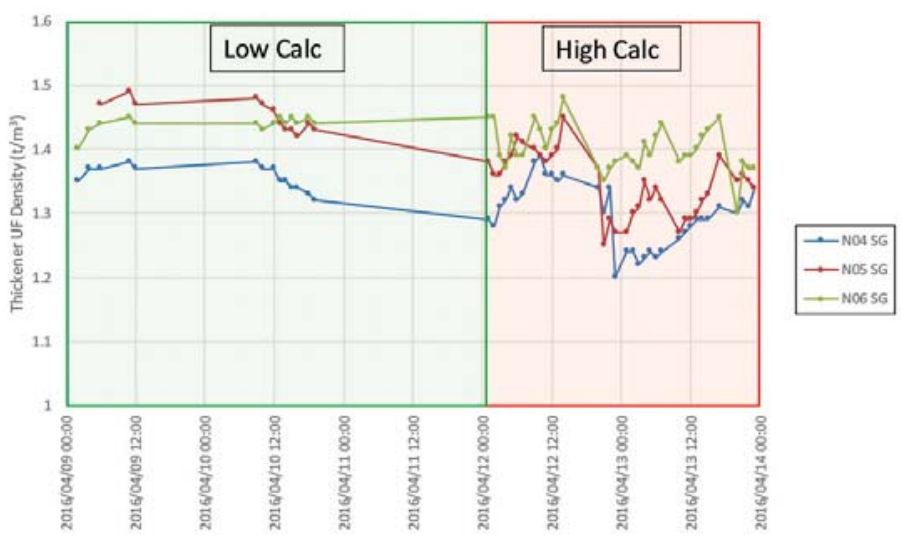

Figure 11-Thickener underflow density in large thickeners

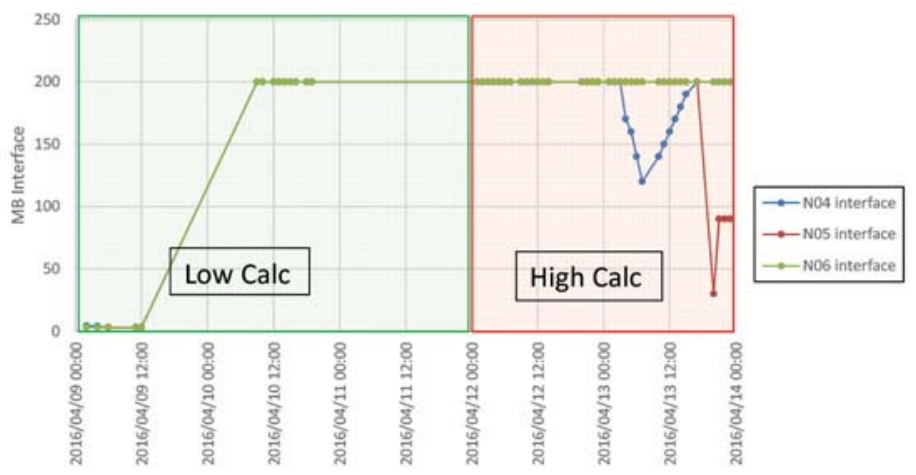

Figure 12-Interface measurements in the large thickeners

\section{SCADA data}

The thickener overflow clarity during the plant campaign is shown in Figure 10. The solution clarity was relatively stable, between 24 and 28 for the normal-calc run. Interestingly, this improved to between 25 and 34 for the high-calc run, but was still mostly below the target clarity of 30 .

This agrees with the data in Figure 7, which shows that the clarity target of 30 is very difficult to achieve at this feed density unless flocculent dosages are increased to approximately $60 \mathrm{~g} / \mathrm{t}$. Currently, the flocculent dosage is maintained at approximately $30 \mathrm{~g} / \mathrm{t}$. Further dilution of the feed would be required to improve clarity levels should the flocculent dosage not be substantially increased.
The underflow densities in the large thickeners were found to decrease for high-calc material. Significantly, the final target density target of 1.45-1.48 could not be achieved in the terminal thickener (thickener 6). This would have implications both for the overall plant water balance and the uranium recovery, as more water and dissolved uranium would report to the slimes dam under high-calc conditions. Based on wash efficiency calculations, it is estimated that a decrease in underflow density in the terminal thickener from 1.45 to 1.39 would result in a $1.0 \%$ loss in recovery, due to increased soluble losses.

It is interesting to note that the underflow densities were fairly erratic for the high-calc period, indicating difficulty in 


\section{Optimization of the Rössing countercurrent decantation circuit for high-calc ore}

maintaining stable conditions using the current control philosophy.

Figure 12 shows that despite the considerable variability in underflow density and overflow clarity during the campaign, the interface measurements were virtually unchanged at $200 \mathrm{~cm}$ in the large thickeners. This indicates that the interface measurement is fairly unreliable for diagnosing the thickener performance. This could be due to the interface measurement being taken from the side of the thickener, far away from the underflow withdraw point in the centre, where the interface may be more variable.

It was noted during the campaign that the feedwells appeared to create 'pluming' on the opposite end of the feed trough, due to the slurry being directed downward into the feedwell instead of tangentially (Figure 13). It is speculated that these flow patterns may be eroding the bed near the feedwell, whereas the bed level at the sides of the thickener is largely unaffected.

\section{Computational fluid dynamics analysis}

A computational fluid dynamics (CFD) model was developed for the existing launder and feedwell using Star CCM+ v11 for mesh generation, solution, and post-processing. The CFD model was able to simulate the flow velocities, flow distribution, strain rate, residence time etc., as well as the location of the ensuing free surface between the flowing slurry and the air. The CFD models applied to this problem used a highly refined mesh with a volume of fluid (VOF)

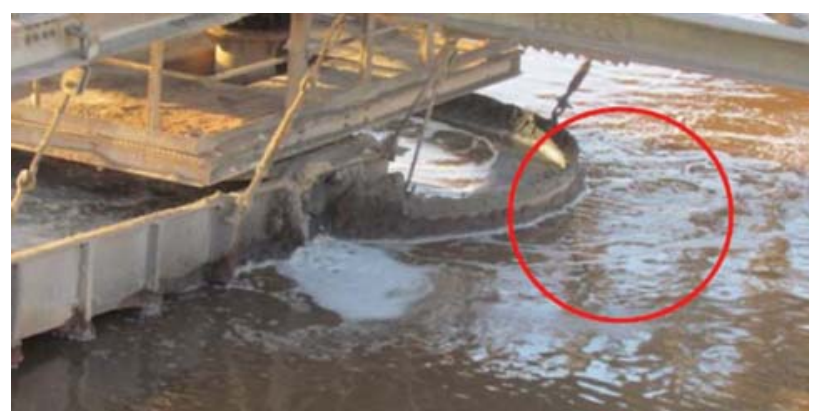

Figure 13-Problematic flow patterns resulting from thickener feedwell arrangement

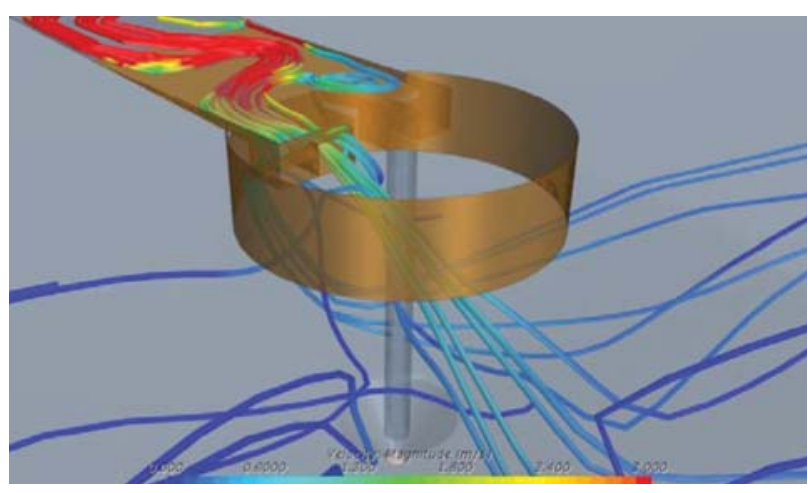

Figure 14-Flow patterns resulting from deflector plates at end of launder model to resolve the slurry-air interface solved with a Reynolds Averaged Navier-Stokes (RANS) solver to timeaverage the turbulent flows in the launder, the flow control vanes, and the feedwell.

Using this tool, the flow patterns in the existing feedwells were further investigated and the mode of discharge into the thickener feedwell was modelled. Flow was found to be directed diagonally downwards by the deflector plates at the end of the launder (Figure 14).

These downward flow patterns are consistent with pluming, which has been observed on the surface of the thickener (refer Figure 13). The flow patterns are also associated with short-circuiting of particles out of the feedwell, and poor mixing of the flocculent.

\section{Summary of findings}

Based on the bench-scale test work, the SCADA data, and the CFD modelling, the key issues affecting the thickener performance appeared to be the feedwell design and the process control methodology. Static sedimentation tests showed that the current feed concentrations of $10-12 \% \mathrm{~m} / \mathrm{m}$ were associated with poor settling rates and poor overflow clarity for both normal and high-calc conditions. A reduction to $6 \% \mathrm{~m} / \mathrm{m}$ (in the feedwell) was likely to produce a substantial improvement in settling rates and overflow clarity for both material types. This is confirmed by site experience, where the plant must run on three mills instead of four when processing high-calc ore, as this dilutes the feed to the CCD circuit, reduces the solids flux rate, and improves settling performance.

The underflow density and overflow clarity were generally found to be highly variable for high-calc ore using the current process control methodology. Tighter control of these parameters would prevent short periods of low underflow density and poor clarity, and thereby improve the average underflow density and overflow clarity.

\section{Recommended circuit modifications}

\section{Alternative feedwell design}

In order to address these issues, modification of the feedwells was investigated. A key aim was to promote a tangential flow pattern within the feedwell to dissipate slurry momentum and promote better mixing of the flocculent with the solids, in line with the recommendations from the literature (Fawell et al., 2009). To achieve this, flow needed to be introduced tangentially into the feedwell, and a shelf was included to create an upper zone for mixing and a lower zone for aggregate growth. The resulting tangential flow pattern increased the slurry residence time in the feedwell and created a volume of improved shear conditions for flocculation.

Following an on-site investigation, it was decided to keep with the existing feed launders rather than replace them with a pipe-fed arrangement. This was partly due to the cost considerations (demolition costs, additional piping, and engineering) and partly because the feed launders were already known to result in significant flocculation of the feed. Furthermore, due to the brownfield environment, it was necessary to minimize the downtime for installing the feedwell modifications. 


\section{Optimization of the Rössing countercurrent decantation circuit for high-calc ore}

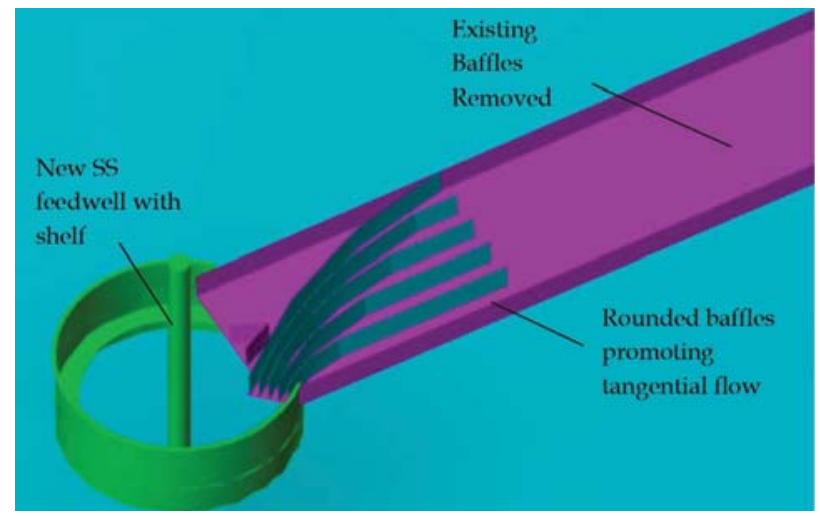

Figure 15-Proposed feedwell modifications

The baffles on the launders were removed in order to promote a more quiescent flow. Rounded stainless steel baffles were welded to direct flow tangentially into the feedwell. The existing fibre-reinforced plastic (FRP) feedwell was replaced with a new stainless steel rubber-lined feedwell with shelf to improve slurry retention time (Figure 15). This concept was tested in the CFD environment (Figure 16) and was found to produce good tangential flow with substantially improved slurry retention time and reduced short-circuiting of slurry out of the feedwell.

The tangential flow patterns produced by the feedwell modifications were found to result in high pressure gradients on the edge of the feedwells. This situation makes the addition of autodilution slots extremely challenging, as a simple opening in the feedwell will not result in liquid flowing into the feedwell to dilute the slurry. When autodilution slots were added to the feedwell, these regions of high pressure

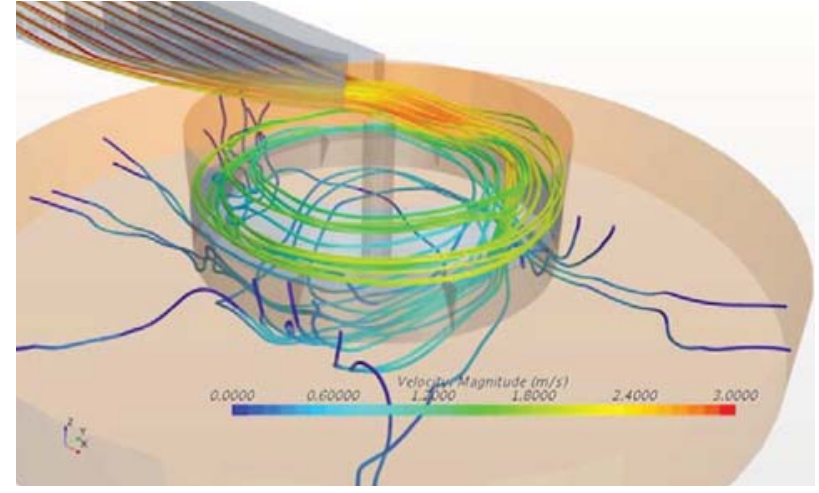

Figure 16-Modified 'shelf' feedwell design

forced slurry out of the feedwell, rather than into the feedwell to dilute the incoming slurry. Various permutations of the autodilution slots were tested; however, the high pressure gradient due to tangential flow meant that liquid was found to consistently flow out of the feedwell, rather than in.

Due to the difficulties in achieving autodilution using the modified feedwell design, Hatch engaged with various vendors to determine whether an alternative, forced dilution system could be implemented. The replacement option was focused on the larger $68.5 \mathrm{~m}$ thickeners, as these thickeners receive a higher feed concentration of $27.3 \% \mathrm{~m} / \mathrm{m}$ solids, compared to $12.3 \% \mathrm{~m} / \mathrm{m}$ solids on the smaller thickeners.

Several of the vendors engaged were not able to make their existing designs fit into the Dorr Oliver and EIMCO thickeners due to the low wall height and truss rake design of these thickeners. This led to tenders for quotations for
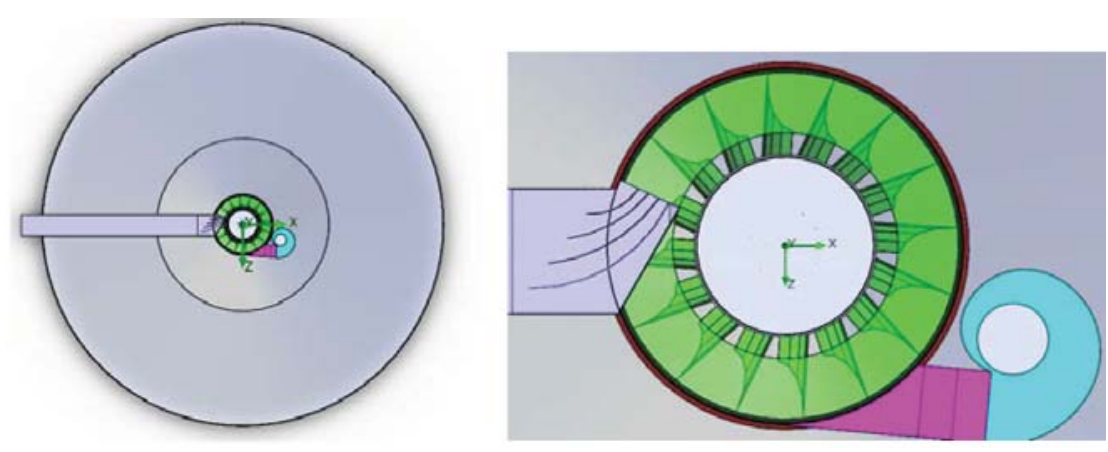

Figure 17-Top view of Radflow feedwell and ETAQ dilution pump retrofit

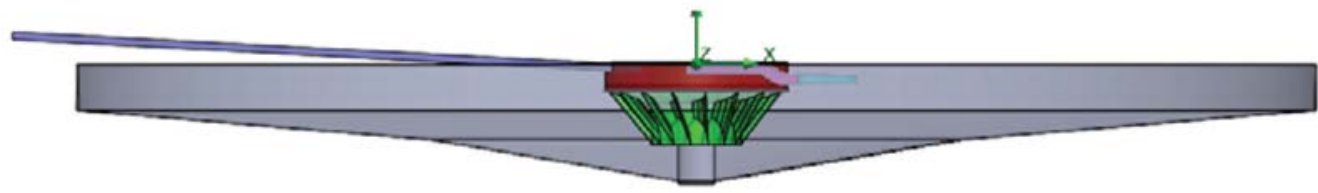




\section{Optimization of the Rössing countercurrent decantation circuit for high-calc ore}

complete replacement of the rake, heightening of the walls, and replacement of the feedwell. The costs were similar to those for total replacement of the thickeners. This was deemed too expensive for the project and was discarded as an option.

One vendor (Roytec) applied a more fit-for-purpose approach of adjusting their feedwell design to match the existing thickener constraints, and proposed a design based on their RadflowTM feedwell with ETAQTM dilution pump (Figures 17 and 18).

As with the modified feedwell design, the design utilizes the existing launder rather than incorporating a pipe feed arrangement. This was done to minimize the cost and complexity of the thickener modification.

The feedwell is designed in two parts, with the upper section fixed to the central torque cage and the lower vanes mounted on the rake. A $600 \mathrm{~mm}$ clearance has been provided to allow for lifting of the rake.

The design incorporates a 1.4 m ETAQ dilution pump (shown in Figure 17 in light blue), which pumps up to $4500 \mathrm{~m} 3 / \mathrm{h}$ of dilution water into the feedwell. This is substantially greater than what the current recycle pumps on the large thickeners can deliver $(852 \mathrm{~m} 3 / \mathrm{h})$. These current pumps are limited by the NPSH and cannot be further upgraded.

Table II compares the feedwell dilution with the current (external) dilution pumps and the proposed ETAQ (internal) dilution pumps. Note that the feed densities for the large thickeners in Table II are higher than the feed density for the

Table II

\section{Comparison of feed dilution options for large $68.5 \mathrm{~m}$ thickeners}

\begin{tabular}{|l|c|c|}
\hline Scenario & $\begin{array}{c}\text { Recycle flow } \\
\text { rate }\left(\mathrm{m}^{3} / \mathrm{h}\right)\end{array}$ & $\begin{array}{c}\text { Solids in } \\
\text { feedwell }(\%, \mathrm{~m} / \mathrm{m})\end{array}$ \\
\hline No dilution pump & 0 & $49.0 \%$ \\
External dilution (current) & 852 & $27.3 \%$ \\
Internal dilution & 4500 & $9.4 \%$ \\
\hline
\end{tabular}

smaller thickeners (refer Table I), since these thickeners are located further down the CCD train and are fed by the underflow of the preceding stage.

The use of internal dilution pumps will enable a substantial reduction in the feed solids concentration from $27.3 \%$ to $9.4 \%$ solids. Further increasing the feed dilution to $6 \% \mathrm{~m} / \mathrm{m}$ was found to be impractical for the large thickeners, due to the limitations of the large custom retrofit feedwell size required to support such large volumes of dilution water. However, it is believed that the reduction to $9.4 \% \mathrm{~m} / \mathrm{m}$ will substantially improve the settling rate and overflow clarity, and reduce flocculent consumption, as per the trend demonstrated in the settling test work (refer Figure 7).

In addition to the higher dilution within the feedwell, the Radflow feedwell incorporates custom-designed vanes, which effectively break the tangential component of the flow as it exits the feedwell. This prevents the vigorous flow within the feedwell from disturbing the bed below.

The Radflow design was found to provide high flow (approx. $2 \mathrm{~m} / \mathrm{s}$ ) and shear within the feedwell (Figure 19), with significant energy dissipation through the vanes below the feedwell. The vanes effectively stop the tangential component of flow as slurry exits the feedwell and project the slurry out radially, at sufficiently low velocity to allow effective settling.

\section{Process control enhancements}

Based on the SCADA data obtained during the high-calc plant trial, the following weaknesses were identified in the current control philosophy:

> Variation of underflow pump speed is not coupled with variation of the flocculent dosage to the downstream thickener, often resulting in under- or overdosing of flocculent

> Manual sampling can only be done at hourly intervals, leading to slow reaction times to process upsets

- Inaccuracy of Marcy scale density data due to sampling and measurement errors

> Bed interface measurement taken at perimeter of thickeners, where changes in the bed characteristics are less apparent.

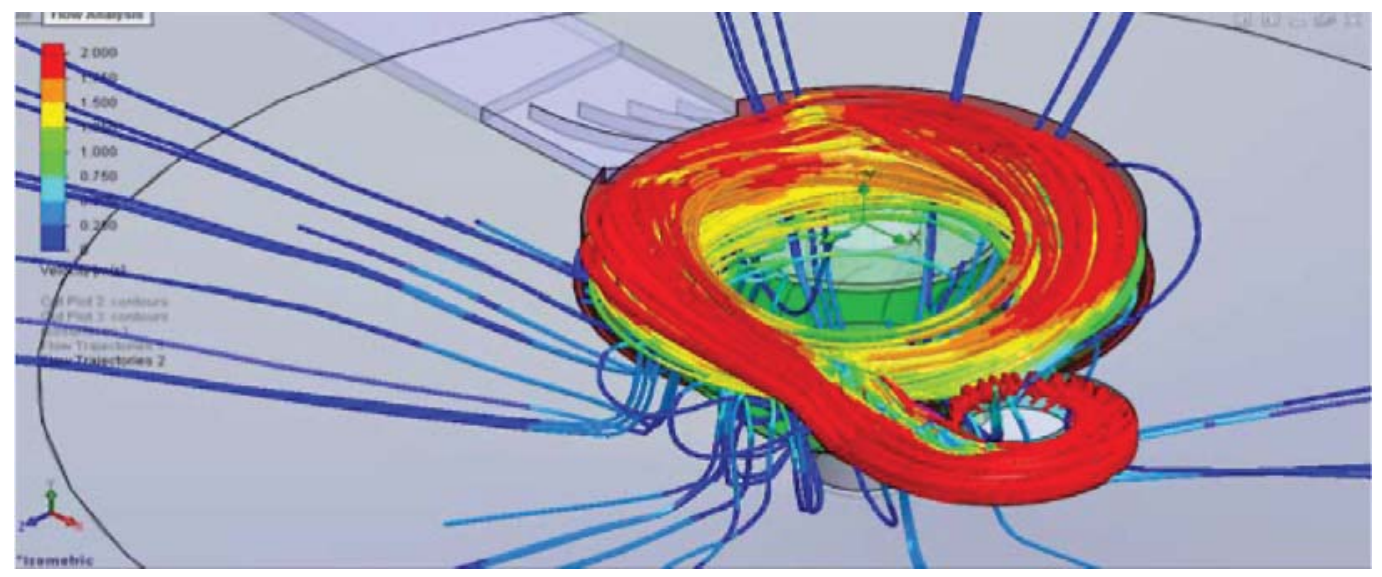




\section{Optimization of the Rössing countercurrent decantation circuit for high-calc ore}

These weaknesses tend to result in high variability of underflow densities, sub-optimal flocculent dosing, belowtarget overflow clarity, and reduced washing efficiency. In particular, the washing efficiency is strongly affected by the density in the terminal thickener, as this thickener determines the water losses to the tailings dam.

In order to improve the overall CCD performance, it is proposed that the thickener control philosophy be automated by installing density probes on the underflow of each thickener and two mud bed interface indicators on the final two thickeners in the train (thickeners 6 and 7).

It is recommended that a total of eight density probes be installed on the CCD circuit; (two per large thickener, as each thickener has two underflow lines). These density meters will be calibrated and wired back to the SCADA system. A density set-point will be set in each thickener and the speed of the underflow pump will be varied to hold the set-point. Thickener torque will also be monitored and the pump speed will increase should the specified torque limit be exceeded.

The density measurement and pump speed will be combined and used as the measured variable for varying the flocculent dosing to the subsequent thickening stage. This means that as the mass of solids reporting to the downstream thickener increases, the flocculent dose will increase accordingly. This improvement will effectively remove the need for manual sampling for underflow density, although overflow clarity will still be monitored and used to adjust the flocculent set-point in terms of grams per ton.

A mud bed level probe will be installed on the terminal thickener (thickener 7) to monitor the mud bed interface to the desired set-point. The intention is to maintain a consistently high mud level in order to maximize the mud bed residence time and consolidation. This is particularly important on the terminal thickener as it will allow the thickener to target the maximum possible underflow density, regardless of the material processed (high-calc $v s$. low-calc).

The mass of slimes pumped to the tailings dam is critical, since this slimes material is mixed with the coarse sands material in the Paddy $\mathrm{X}$ tailings system and provides a suspension medium for pumping. Should insufficient slimes be available, the integrity of the tailings pumping system is put at risk. For this reason, it was important to include a mud bed interface indicator on thickener 6 as well as thickener 7 to maintain a high level of slimes inventory. At times when thickener 7 is bypassed, thickener 6 will run as the terminal thickener and must provide the maximum underflow density to ensure good wash efficiency is maintained.

\section{Conclusion}

The Rössing Uranium CCD circuit has come under increasing pressure in recent years due to the addition of high-calc ore to the circuit. This material was found to be associated with poor overflow clarities and reduced underflow densities.

In order to quantify the reasons for poor performance, bench-scale test work on the thickener feed was undertaken. This test work suggested that good thickener performance could still be obtained for high-calc ore provided conditions were optimized. Key areas identified for optimization were the feed density and process control.
Two alternative feedwell designs were developed to improve settling performance: one simple shelf design, and one RadflowTM design with an internal pump for forced dilution. It was recommended that the shelf design be implemented on the smaller thickeners where feed dilution is less important. The forced dilution feedwells are recommended for implementation on the larger thickeners, which are supplied with a higher feed concentration.

An automated control system was also devised, comprising eight density meters and two mud bed interface indicators. This will improve the consistency of underflow densities and allow the flocculent to be controlled automatically based on the feed from the preceding stage.

These changes are currently being phased in at Rössing, with the first feedwell planned for the terminal thickener (thickener 7) and the process control upgrades planned for the large thickeners.

\section{Acknowledgements}

The authors gratefully acknowledge the support of Rössing Uranium in allowing us to present this paper. In particular, the inputs of Mr Rudolf Shipapo, Mr Messag Kamati, and Ms Leilanie Feris are gratefully acknowledged. The authors would also like to thank Vietti Slurrytec, who assisted with the test work and analysis. Duane Baker and Jennifer Woloshyn of the Hatch Special Engineering and Design Group are acknowledged for their CFD analysis of the existing feedwell, as well as the testing of the modified 'shelf' feedwell concept. The inputs from Roytec in developing the forced dilution feedwell design are also gratefully acknowledged, in particular Alex Krassnokutski, who tested the Radflow design, both in the CFD environment and using various scale models.

\section{References}

Fawell, P.D., Farrow, J.B., Heath, A.R., Nguyen, T.V., Owen, A.T., Paterson, D. Rudman, M., Scales, P.J., Simic, K., Stephens, D.W., SwiFt, J.D., and Usher, S.P. 2009. 20 years of AMIRA P266 'Improving Thickener Technology' How has it changed the understanding of thickener performance? Paste 2009: Proceedings of the 12th International Seminar on Paste and Thickened Tailings, Viña del Mar, Chile, 21-24 April 2009. Australian Centre for Geomechanics, Nedlands, Western Australia. pp. 21-24.

KRASSNoKUTSKI, A. 2012a. RadflowTM - The next generation feedwell. Paste 2012: Proceedings of the 15th International Seminar on Paste and Thickened Tailings, Sun City, Pilanesberg, South Africa, 16-19 April 2012. Australian Centre for Geomechanics, Nedlands, Western Australia. pp. 121-128.

KRASSNOKUTSKI A., 2012b. Development of the next generation thickener featuring the RadflowTM feedwell technology. Proceedings of Procemin 2012, Santiago, Chile. Doll, A., Kracht, W., and Kuyvenhoven, R. (eds). Gecamin Ltda, Santiago.

TRiglavcanin, R.A. 2008. The heart of thickener performance. Paste 2008: Proceedings of the Eleventh International Seminar on Paste and Thickened Tailings, Kasane, Botswana, 5-8 May 2008. Fourie, A., Jewell, R., Slatter, P., and Paterson, A. (eds.). Australian Centre for Geomechanics, Nedlands, Western Australia. pp. 63-81. 